\title{
The prosody of focus in the Spanish of Quechua-Spanish bilinguals: A case study on noun phrases
}

International Journal of Bilingualism 2014, Vol. 18(6) 614-632

(C) The Author(s) 2012

Reprints and permissions:

sagepub.co.uk/journalsPermissions.nav DOI: $10.1177 / 1367006912456103$ ljb.sagepub.com

@SAGE

\section{Remy van Rijswijk and Antje Muntendam}

Department of Linguistics, Center for Language Studies, Radboud University Nijmegen, The Netherlands

\begin{abstract}
This study examines the prosody of focus in the Spanish of 16 Quechua-Spanish bilinguals near Cusco, Peru. Data come from a dialogue game that involved noun phrases consisting of a noun and an adjective. The questions in the game elicited broad focus, contrastive focus on the noun (non-final position) and contrastive focus on the adjective (final position). The phonetic analysis in Praat included peak alignment, peak height, local range and duration of the stressed syllable and word. The study revealed that Cusco Spanish differs from other Spanish varieties. In other Spanish varieties, contrastive focus is marked by early peak alignment, whereas broad focus involves a late peak on the non-final word. Furthermore, in other Spanish varieties contrastive focus is indicated by a higher F0 maximum, a wider local range, post-focal pitch reduction and a longer duration of the stressed syllable/word. For Cusco Spanish no phonological contrast between early and late peak alignment was found. However, peak alignment on the adjective in contrastive focus was significantly earlier than in the two other contexts. For women, similar results were found for the noun in contrastive focus. An additional prominence-lending feature marking contrastive focus concerned duration of the final word. Furthermore, the results revealed a higher F0 maximum for broad focus than for contrastive focus. The findings suggest a prosodic change, which is possibly due to contact with Quechua. The study contributes to research on information structure, prosody and contact-induced language change.
\end{abstract}

\section{Keywords}

Bilingualism, prosody, focus, Quechua, Spanish, noun phrase

Corresponding author:

Antje Muntendam, Department of Linguistics, Center for Language Studies, Radboud University Nijmegen, Postbus 9103, 6500 HD Nijmegen, The Netherlands.

Email: a.muntendam@let.ru.nl 


\section{Introduction}

According to Thomason and Kaufman (1988; Thomason, 2001), contact-induced change is possible at all linguistic levels. However, some are more vulnerable to change than others. Phonological and lexical elements are commonly transferred. Syntactic transfer does not seem to occur as frequently; it has been demonstrated that contact-induced change that at first glance appeared to involve syntax is often the result of a pragmatic influence (Muntendam, 2009, 2013; Silva-Corvalán, 2008).

Several studies show that the prosodic system can be affected by contact with another language. Bullock (2009) found prosodic innovations in the heritage French of French-American English bilinguals, due to English. Moreover, Elordieta (2003) demonstrated that Basque-Spanish bilinguals differ in their Spanish intonation from both Peninsular Spanish and Basque monolinguals. In Simonet's $(2008,2011)$ study on Majorcan Catalan-Spanish bilinguals, Spanish-dominant speakers adopt features of Catalan intonation in their Spanish. Furthermore, Colantoni and Gurlekian (2004) found that Spanish monolinguals in Buenos Aires have different intonation patterns from speakers of other Spanish varieties. This was attributed to contact with Italian. To determine whether the nature of the prosodic change depended on the specific languages involved or was due to language contact per se, Colantoni (2011) compared two contact situations in Argentina: Spanish-Italian and Spanish-Guarani. Because the two situations led to different results, she concluded that the characteristics of the languages determined the exact prosodic change.

Simonet $(2008,2011)$ and Colantoni and Gurlekian (2004) explain prosodic change in SpanishCatalan and Spanish-Italian contact, respectively, as the result of 'convergence', a process in which two similar languages become more similar after contact. For Quechua and Spanish, two typologically unrelated languages, convergence has been proposed to explain contact-induced change at the syntax-pragmatic level (Sánchez, 2003). O'Rourke $(2005,2012)$ and Muntendam (2012) found that the Spanish prosody of Quechua-Spanish bilinguals in Peru differed from that of other Spanish varieties, possibly due to contact with Quechua. The question remains whether this is also an instance of convergence.

The present study will further examine Spanish prosody in contact with Quechua. Specifically, it attempts to shed more light on the use of prosody by Quechua-Spanish bilinguals from Cusco, Peru, to express broad and contrastive focus in the Spanish noun phrase (NP).

Most research on prosody concerns read speech, including studies on Peruvian Spanish and Quechua (O'Rourke, 2005, 2009, 2012). Face (2003) demonstrated considerable differences between the intonation of read and semi-spontaneous speech and argued that it is important to examine both forms. Colantoni (2011) compared semi-spontaneous speech to read speech for Argentinean Spanish to establish whether there was a task effect. For the present study a dialogue game was designed, in which participants described colored objects. These semi-spontaneous data will complement O'Rourke's $(2005,2012)$ findings.

The paper is organized as follows. Firstly, we will discuss focus, its relation with prosody in Spanish and Quechua and previous studies on Spanish prosody in contact with Quechua. Subsequently, the research questions will be outlined. In the following sections, we will present the methods used for collecting and analyzing the data, and the results. We will end with the discussion and conclusion.

\section{Focus in Spanish}

Focus can be understood through two dimensions (Gussenhoven, 2007). The first concerns the scope of focus, that is, broad versus narrow focus. Broad focus involves the whole sentence. When 
only one element is focused, it is in narrow focus. The second dimension distinguishes several meanings of focus. Neutral focus is the new information that answers a wh-question. Contrastive focus, on the other hand, occurs when information is rejected and changed into a new value.

Languages have different strategies to mark focus. Spanish uses syntax and prosody. Syntactically, focus can be marked by a word order change, as in focus fronting (Zubizarreta, 1999). Because for this study only prosody is relevant, we will leave syntax aside.

Several studies on Spanish describe the prosodic differences between broad and contrastive focus (De-la-Mota (1997) for Peninsular Spanish; Face (2001, 2002) and Face \& D'Imperio (2005) for Madrid Spanish). Firstly, a difference has been found in F0 peak alignment on the non-final word. A non-final word in broad focus involves a 'late peak', falling in the post-tonic syllable, whereas in contrastive focus it is accompanied by an 'early peak', falling within the stressed syllable. Late alignment can also be observed on a word in contrastive focus, but with a significantly higher pitch than in broad focus. The accent on the final word involves early alignment in both broad and contrastive focus (Face \& D'Imperio, 2005).

The same phonological contrast between early and late alignment of the prenuclear (i.e. nonfinal) peak was found in later studies for Castilian Spanish (Estebas-Vilaplana \& Prieto, 2010), Cantabrian Spanish (López-Bobo \& Cuevas-Alonso, 2010), Canarian Spanish (Cabrera-Abreu \& Vizcaíno-Ortega, 2010), Ecuadorian Andean Spanish (O'Rourke, 2010) and Venezuelan Andean Spanish (Astruc, Mora \& Rew, 2010). The contrast was not found in Puerto Rican Spanish (Armstrong, 2010), Mexican Spanish (Kim \& Avelino, 2003), Dominican Spanish (Willis, 2010) and Argentinean Spanish (Gabriel et al., 2010). Concerning the nuclear (i.e. final) peak, considerable variation has been found across varieties (see Prieto and Roseano (2010) for an overview).

An additional prominence-lending feature of contrastive focus is a wider range in F0 (O'Rourke (2005) for Lima Spanish). Also, the word in contrastive focus can be followed by post-focal pitch reduction (Face $(2001,2002)$ for Madrid Spanish). Furthermore, contrastive focus can be associated with a longer duration of the stressed syllable, word and sentence (De-la-Mota (1997) for Peninsular Spanish, Face (2002) for Madrid Spanish, and Kim \& Avelino (2003) for Mexican Spanish).

The above-mentioned studies concern the prosody of focus at the sentence level. According to Zubizarreta (1999), there is a similar interaction between prominence and contrastive focus within the NP. In (1a), with the most prominent accent on the final word of the NP, ambiguity arises. The focus can be on rojas, 'red', botas rojas, 'red boots', or el gato de botas rojas, 'the cat with the red boots'. When the most prominent accent falls on a non-final word (1b), the only plausible reading is that that word is in contrastive focus:

(1) a. El gato de botas ROJAS comió un ratón.

b. El gato de BOTAS rojas comió un ratón.

'The cat with the red boots ate a rat.'

(Zubizarreta, 1999, pp. 4230-4231).

Although in Spanish certain adjectives can precede the noun, the NPs elicited in this study follow the order noun-adjective.

\section{Focus in Quechua}

The canonical word order of Quechua is subject-object-verb (SOV) but word order is relatively free (Cerrón-Palomino, 1987). At the sentence level, focus is marked morphologically and 
syntactically. Morphologically, the morpheme $-m i(-n /-m$ after a vowel) is used to indicate focus (2). It also has an evidential meaning, expressing direct experience (Faller, 2002; Muysken, 1995).

Focused elements can remain in situ; in (2), with SOV, the direct object wasi, 'house', is marked for focus. Focus can also be preposed to the left-periphery of the sentence; in (3) the direct object $t^{\prime}$ 'anta, 'bread', is preposed and marked with $-m i{ }^{1}$

(2) Pidru wasi-ta-n ruwa-n.

Pedro house-ACC-FOC make-3SG

'It is a house that Pedro builds.' (Muysken, 1995, p. 380)

(3) T'anta-ta-m Huwan miku-ru-n.

Bread-ACC-FOC Huwan eat-PERF-3SG

'It was bread that Juan ate.' (Sánchez, 2010, p. 65)

As for the prosody of focus, Cole (1982) found that in Imbabura Quechua, a variety spoken in Ecuador, contrastive focus was associated with a peak on the penultimate syllable of the contrasted word. This peak was generally higher than in broad focus. A specific intonation contour for focus was not found for Southern Peruvian Quechua (Cusihuamán, 1976/2001; O'Rourke, 2005; Parker, 1969; Samanez-Flórez, 1996). In a recent acoustic analysis of broad focus declaratives in Cusco Quechua, O'Rourke (2009) showed early peak alignment for both final and non-final words. Although O'Rourke (2009) did not analyze narrow focus, she showed that sentence-initial subjects marked with $-m i$ received prominence. Specifically, their peak was higher than subsequent peaks (O’Rourke, 2009, p. 304).

While focus at the sentence level is marked syntactically and morphologically, this is not possible within the NP. In Quechua, the adjective always precedes the noun. Furthermore, the morpheme $-m i$ is constituent-external; $-m i$ on the noun marks focus on the entire NP (4). It cannot appear on the adjective to encode narrow focus (5).

(4) Allin runa-n chahay tayta-qa

Good man-FOC this man-TOP

'This man is a good person.'

(5) *Allin-mi runa chahay tayta-qa

Good-FOC man this man-TOP

'This man is a good person.' (Cusihuamán, 1976/2001, p. 110)

To summarize, in the Cusco Quechua sentence focus is expressed morphologically and syntactically. The entire NP can be marked for focus by means of -mi, but within the NP focus is not encoded in the morphology or the syntax. Prosody appears to play a limited role in focus marking.

\section{Prosodic change in Spanish in contact with Quechua}

O'Rourke (2005) compared the prosody of Spanish monolinguals from Lima with that of Spanish monolinguals and Quechua-Spanish bilinguals from Cusco, based on a reading task. The results showed that most Lima participants used early peak alignment for non-final words in contrastive focus, but late alignment in broad focus. Also, post-focal peaks were often significantly lower for contrastive focus than for broad focus, and sometimes the peak on the subject in contrastive focus 
was higher (O'Rourke, 2005). Furthermore, the tonal range was wider for focused words and narrower for post-focal words. Previously reported differences in duration (De-la-Mota (1997) for Peninsular Spanish and Face (2001) for Madrid Spanish) were not found.

Most Cusco participants showed fewer prominence-lending features than the Lima participants when expressing contrastive focus in non-final position. Post-focal peaks were not significantly lower in many cases and no differences in peak alignment were found between contrastive and broad focus (O'Rourke (2005); see also O'Rourke (2012)). Also, peaks were higher and both the global and the local pitch range of words in contrastive focus were wider for broad focus than for contrastive focus (O'Rourke, 2005). Given the contact situation in Cusco, O'Rourke $(2005,2012)$ tentatively suggests that the differences between Lima and Cusco participants are due to an influence of Quechua, where focus is not marked prosodically.

\section{Research questions}

This study examines the prosody of broad and contrastive focus in the Spanish of Quechua-Spanish bilinguals. Specifically, the study concerns NPs with an object and a color (6):

(6) Estrella verde
star green
'Green star.'

As discussed above, Quechua word order within the NP is adjective-noun. A syntactic influence from Quechua on Spanish regarding the order of noun and adjective was not expected, since this was not found by Zavala (1999).

The research questions are as follows: (a) Do Quechua-Spanish bilinguals use prosody to express broad and contrastive focus within the Spanish NP similarly to speakers of other Spanish varieties? (b) If not, how does Cusco Spanish differ from other varieties?

To answer these questions, a phonetic analysis, including peak alignment, F0 maximum, local range and duration of the stressed syllable and word was performed for the noun and adjective. If the prosody of focus in Cusco Spanish is comparable to most Spanish varieties, we predict late alignment of the prenuclear accent for broad focus and early alignment for contrastive focus. We also expect additional prominence-lending features accompanying the word in contrastive focus, for example, a higher F0 maximum, post-focal pitch reduction, a wider local range and longer durations of the stressed syllable and word. Possible differences between Cusco Spanish and other Spanish varieties could be due to contact with Quechua, given that studies on Quechua suggest that the role of prosody in focus marking is limited.

\section{Methodology}

\section{Participants}

The participants were 16 Quechua-Spanish bilinguals from Conchacalla, a community approximately 22 miles from Cusco. Their ages ranged between 23 and 47 years (mean $=33.25)$. Both gender and type of bilingual (sequential and simultaneous) were equally balanced. The simultaneous bilinguals learned Spanish and Quechua at the same time, whereas the sequential bilinguals acquired Quechua before Spanish. They usually acquired Spanish at the age of four. Most participants' parents had Quechua as their first language; some had no or limited knowledge of Spanish. 
All participants used Spanish and Quechua daily. Fourteen participants reported to express themselves equally well in both languages; one participant was more fluent in Spanish, and one expressed herself better in Quechua.

The participants varied in their level of education. There were six professionals: these participants received more education than secondary school. Seven participants were non-professional: they did not receive more than elementary or secondary school education. The remaining three participants did not finish their post-secondary education. Table 1 summarizes the sociolinguistic background information.

Table I. Sociolinguistic background information.

\begin{tabular}{clllll}
\hline Participant & Gender & Age & Bilingual type & Educational level & Occupation \\
\hline I & F & 35 & Simultaneous & Secondary education & Housewife/farmer \\
2 & M & 4 I & Simultaneous & Secondary education & Farmer \\
3 & M & 28 & Simultaneous & University (zootechnics) & Student \\
4 & F & 47 & Sequential & Elementary education & Housewife \\
5 & F & 26 & Simultaneous & Tourism college (unfinished) & Housewife \\
6 & M & 24 & Simultaneous & Husbandry college & Trainee kiwicha cultivation \\
7 & F & 24 & Sequential & University (administration) & Student/storekeeper \\
8 & M & 30 & Simultaneous & Artistic constructions college & Manager workplace \\
9 & F & 23 & Sequential & Nurse college & Student \\
10 & M & 45 & Sequential & Secondary education (unfinished) & Farmer/electrician \\
II & M & 29 & Simultaneous & Gastronomy college (unfinished) & Farmer \\
I2 & M & 42 & Sequential & Elementary education & Construction worker/farmer \\
I3 & F & 43 & Sequential & University (pedagogy) & Teacher elementary school \\
I4 & F & 23 & Simultaneous & Administration college (unfinished) & Storekeeper/farmer \\
I5 & M & 37 & Sequential & Secondary education & Construction worker/farmer \\
I6 & F & 35 & Sequential & Secondary education (unfinished) & Housewife \\
\hline
\end{tabular}

\section{Materials}

For this study, a sociolinguistic background questionnaire and a dialogue game were used. The game was inspired by Swerts, Krahmer, and Avesani (2002). In their study, two participants described cards with geometric figures in different colors by turns. In contrast, the present study involved different objects and question-answer pairs to elicit broad, neutral narrow and contrastive focus in Spanish and Quechua. This paper is limited to the study of broad and contrastive focus in Spanish. The game elicited relatively natural speech; the researcher stayed in the background while the participants were playing.

The materials consisted of cards with drawings of daily life objects (see Figure 1). ${ }^{2}$ Words with voiced consonants (especially after the onset) were selected for the target NPs because voiceless consonants cause a break in the F0 contour. Only words with penultimate stress were included to be able to examine peak alignment. The words had two or three syllables; $85 \%$ of the stressed syllables were open and 15\% were closed. Mainly words with a Quechua equivalent were selected to avoid Spanish loanwords in the Quechua task.

There were 100 question and 100 answer cards. The latter consisted of 20 objects (nouns) in five colors (adjectives); each color was used with four different nouns. All 20 target answers 


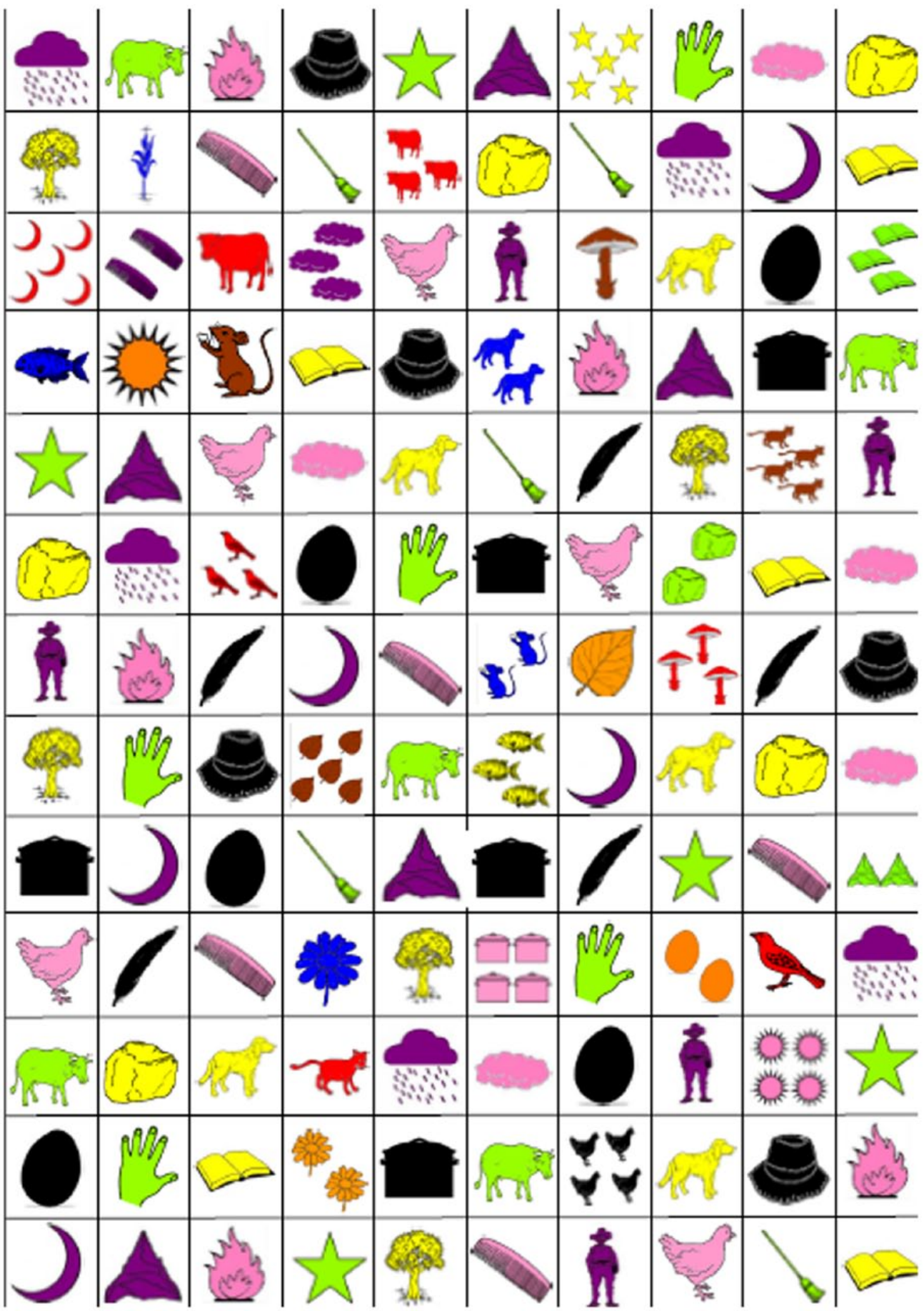

Figure I. Overview of the cards. 
occurred with five focus contexts, elicited by the preceding question: broad focus, neutral narrow focus on the noun and on the adjective, and contrastive focus on the noun and on the adjective.

To elicit broad focus, a white card with a question mark in the upper right corner was used. The answer card had a colored object (see Figure 2), for example, (7):
A: ¿Qué tienes?
'What do you have?'
B: Tengo un toro verde.
'I have a green bull.'

The question card used to elicit contrastive focus on the noun (contr. N) had a colored object, for example, a green sun. The corresponding answer card depicted a different object in the same color, for example, a green bull (see Figure 3). This gives the question-answer pair in (8), in which the answer negates a value and gives an alternative. Because grammatical newness can be expressed by intonation (Cruttenden, 2006), contr. N was elicited using a noun of the same gender.
A: ¿Tienes un sol verde?
'Do you have a green sun?'
B: No, tengo un toro verde.
'No. I have a green bull.'

In the case of contrastive focus on the adjective (contr. A), the objects in the question and answer cards were identical, but the colors differed (see Figure 4) (9):

(9) A: ¿Tienes un toro naranja?

'Do you have an orange bull?'

B: No, tengo un toro verde.

'No. I have a green bull.'

There were also questions to elicit neutral narrow focus on the noun and adjective. To add variation, there were 10 fillers with drawings of other objects in four colors. When the question and
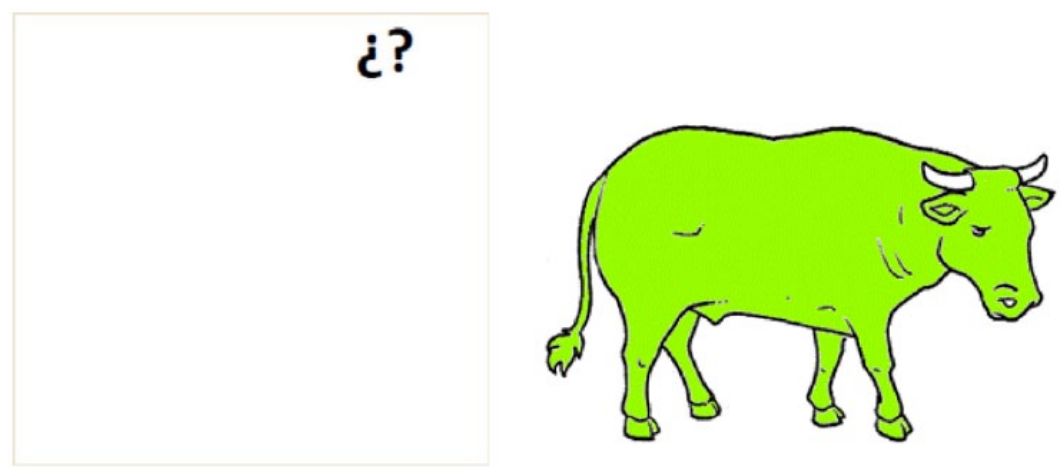

Figure 2. Question card and answer card used for broad focus. 

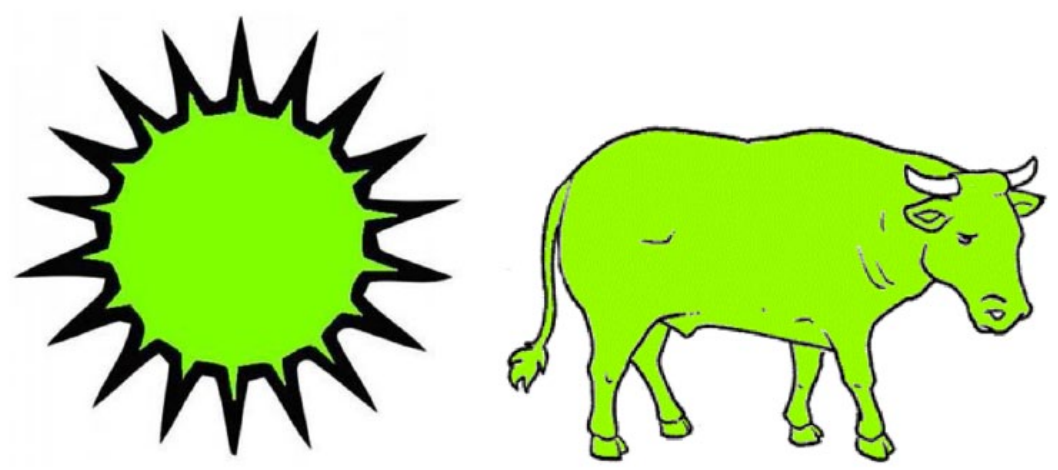

Figure 3. Question card and answer card used for contr. N.

answer cards were identical, the answer was 'yes'. There were also 20 distractor question-answer pairs, for example, (10):

(10) A: ¿Tienes tres perros azules?

'Do you have three blue dogs?'

B: No, tengo dos perros azules.

'No. I have two blue dogs.'

In total, each participant had 260 cards (130 question and 130 answer cards), which appeared in a quasi-random order. The participants asked and answered questions by turns; at the end of the task both participants had asked and answered the same questions. They also had a sheet of paper with an overview of the cards the other player had to describe. The participants were instructed to cross off each card they heard, which encouraged them to describe the cards accurately.
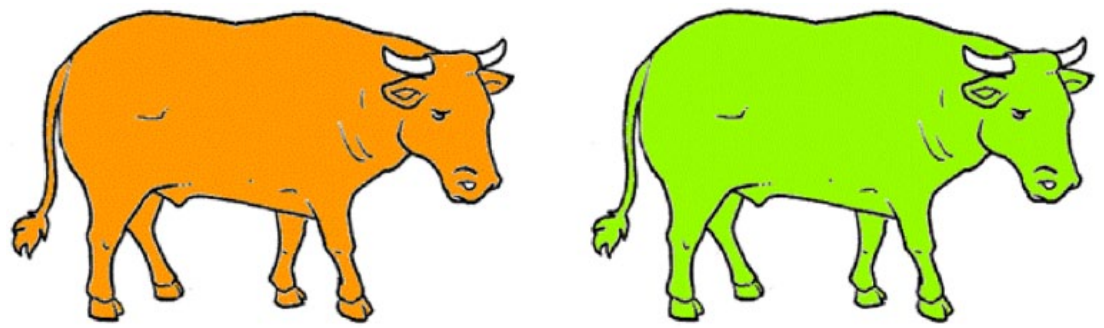

Figure 4. Question card and answer card used for contr. A.

\section{Procedures}

The data were collected by the first author, a white European and second language speaker of Spanish with basic knowledge of Quechua. Prior to the game, the participants received instructions; they were shown several cards and the words for the objects and colors were discussed. This was followed by a practice session with different cards, in which the participants asked and answered 14 questions. The sessions were recorded with a Sony MiniDisc 
Recorder MZ-NH700 and a Sony ECM-MS907 microphone. The task lasted 45-90 minutes per language.

\section{Data analysis}

The data were transferred to a computer using Audacity (Mazzoni \& Dannenberg, 2010). Praat (Boersma \& Weenink, 2010) was used for the analysis. For each noun and adjective peak location, F0 maximum, local range and duration of the stressed syllable and word were measured.

Following Face $(2001,2002)$, peak location was measured in milliseconds, starting from the end of the stressed syllable. Negative values refer to early peak alignment, whereas positive values indicate late alignment.

All Hertz values $(f)$ were converted to equivalent rectangular bandwidth (ERB) units (11):

(11) $E R B=16.6 * \log (1+f / 165.4)$

(Hermes \& Van Gestel, 1991, p. 97; Van Leyden \& Van Heuven, 2006, p. 159).

Because prominence is a relative concept (Swerts et al., 2002), the difference between the F0 maximum on the noun and on the adjective was calculated as well.

The local range of the noun and adjective were calculated as the difference between the F0 maximum and the preceding F0 minimum or valley, following O'Rourke (2005). The relative local range was calculated as the difference between the local range on the noun and that on the adjective.

The durations of the stressed syllable and word were measured in milliseconds. In addition, the differences between the adjective and the noun were examined.

Only words pronounced with penultimate stress were included. Given that the data were recorded in a natural setting, there was some background noise. When the noise coincided with a word, it was excluded from the analysis. Tokens with a break in the F0 contour were not included in the analysis of peak location, F0 maximum and local range. Non-fluent utterances involving laughter, hesitations or pauses were also excluded.

The statistical analysis was performed using $R$ (R Development Core Team, 2011) and the $R$ packages lme4 (Bates, Maechler, \& Bolker, 2011) and languageR (Baayen, 2011). Linear mixedeffects models were used with Subject and Item as random effects (Baayen, Davidson, \& Bates, 2008). The fixed effects were Focus (broad, contr. N and contr. A) and Gender (male, female). Education and Type of Bilingual were excluded, because this led to better-fit models. ${ }^{3} P$-values based on Markov chain Monte Carlo (MCMC) sampling are reported. A Bonferroni correction was applied and thus all effects are reported at a .0167 level of significance.

\section{Results}

\section{Peak alignment}

Figures 5-7 show typical intonation contours for broad focus, contr. $\mathrm{N}$ and contr. A. The results for peak location in milliseconds are summarized in Table 2.

Table 2 shows negative means for all focus types, indicating early peak alignment for most words. An analysis of the proportions shows that $72.4 \%$ of the nouns in broad focus and $71.3 \%$ in both contr. $\mathrm{N}$ and contr. A were aligned early. The percentages for early peaks on the adjective are $83.0 \%$ for broad focus, $81.9 \%$ for contr. $\mathrm{N}$ and $87.9 \%$ for contr. A. These proportions suggest that potential differences lies in peak location rather than in peak alignment. 


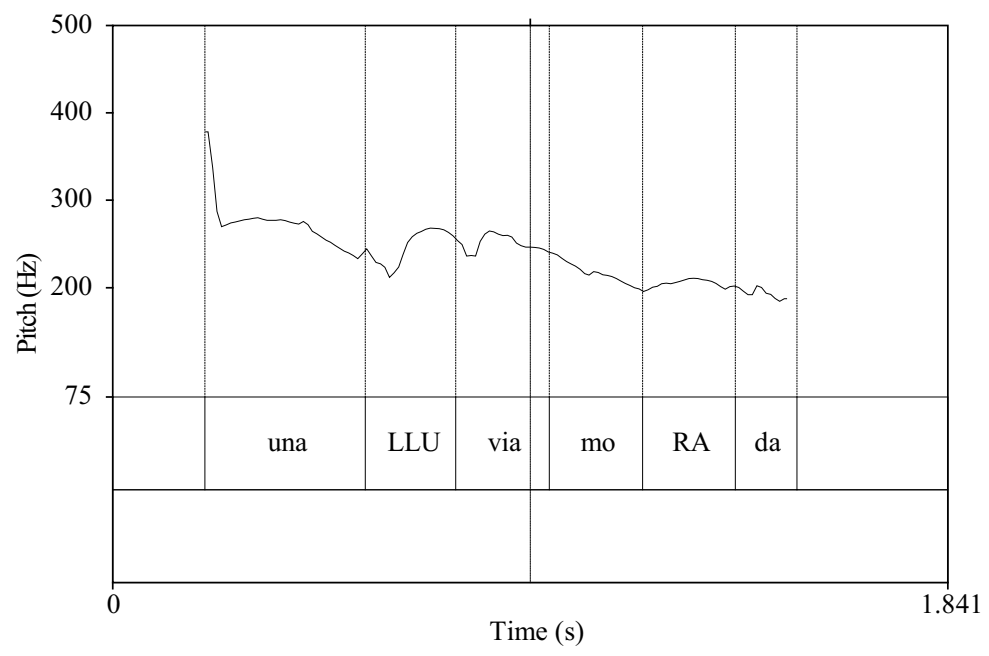

Figure 5. F0 contour of the noun phrase una lluvia morada, 'a purple rain', in broad focus.

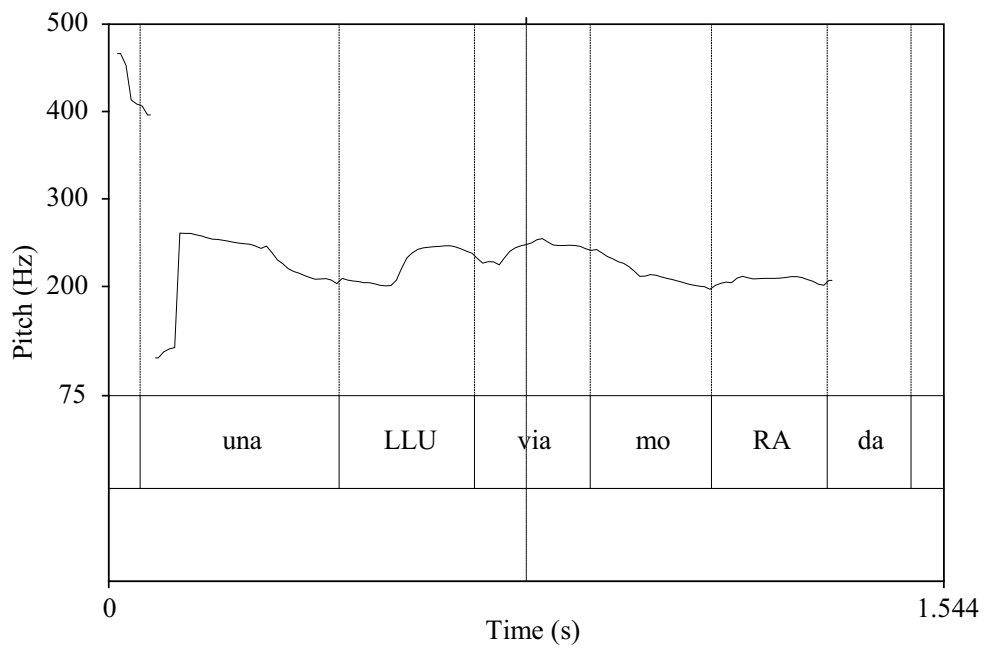

Figure 6. F0 contour of the noun phrase una lluvia morada, 'a purple rain', in contr. N.

For peak location on the noun, a significant effect was found between contr. $\mathrm{N}$ and contr. $\mathrm{A}, \beta=$ $-0.0267, t=-2.4, p=.010$. Overall, the noun is significantly earlier in contr. $\mathrm{N}($ mean $=-28.75)$ than in contr. A (mean $=-24.10$ ) (Table 2). An interaction was found for Gender versus contr. $\mathrm{N}$ and contr. A, $\beta=0.0455, t=2.9, p=.002$. Deeper inspection reveals that men and women showed opposite patterns: women used earlier alignment for contr. $\mathrm{N}($ mean $=-42.22)$ than for contr. A $($ mean $=-16.84)$, while men used earlier peaks for contr. A (mean $=-31.91)$ than for contr. $\mathrm{N}$ (mean $=-14.21)$. At present we do not have an explanation for this difference between men and women. It should also be noted that the standard deviations were large, which could be explained by a high intra- and/or inter-speaker variation. A detailed analysis of this variation is beyond the scope of this paper. 


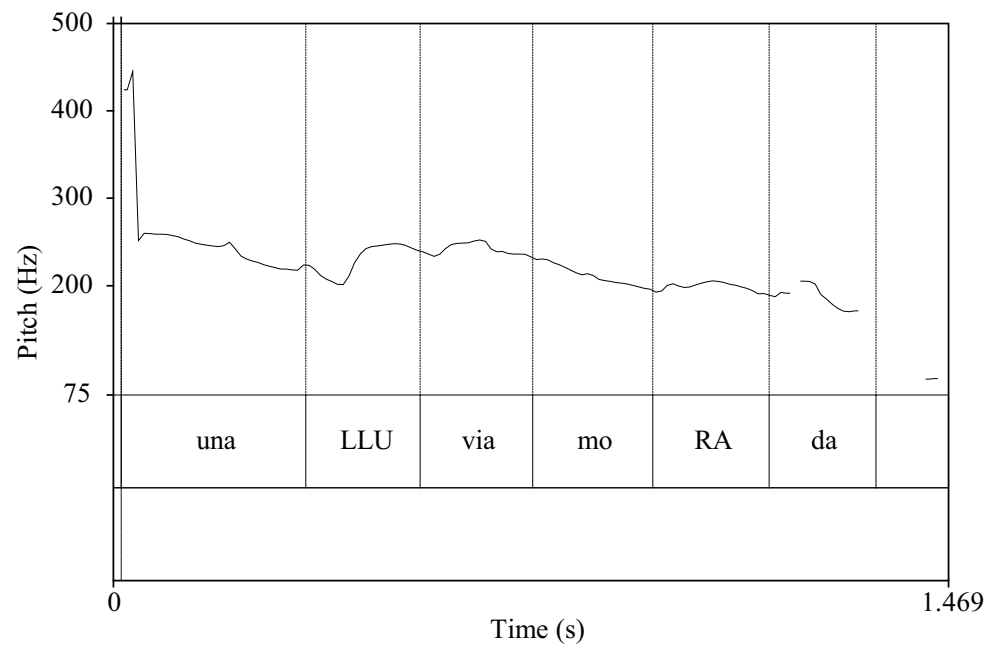

Figure 7. F0 contour of the noun phrase una lluvia morada, 'a purple rain', in contr. A.

Table 2. Peak location on the noun and the adjective for three focus types (in ms).

\begin{tabular}{lllllllr}
\hline Focus type & Noun & \multicolumn{5}{l}{ Adjective } \\
\cline { 2 - 3 } \cline { 7 - 8 } & N & Mean & SD & & $N$ & Mean & SD \\
\hline Broad & 229 & -28.61 & 89.73 & & 179 & -96.69 & 97.90 \\
Contr. N & 237 & -28.75 & 97.02 & & 176 & -91.20 & 101.01 \\
Contr. A & 220 & -24.10 & 92.30 & & 191 & -116.09 & 99.08 \\
\hline
\end{tabular}

For peak location on the adjective, there was a significant difference between broad focus and contr. A, $\beta=0.0327, t=2.6, p=.004$, and between contr. A and contr. $\mathrm{N}, \beta=0.0365, t=3.0, p=$ .002 . The peak on the adjective is significantly earlier in contr. A than in the other focus contexts. This holds for men and women.

In sum, the results indicate that in Cusco Spanish the contrast between early and late alignment is not used to distinguish between broad focus, contr. $\mathrm{N}$ and contr. A, unlike in many other Spanish varieties (e.g. De-la-Mota [1997] for Peninsular Spanish; Face [2001] for Madrid Spanish). Similar results were found for some other varieties (e.g. O'Rourke [2005, 2012] for Cusco Spanish; Willis [2010] for Dominican Spanish). Interestingly, in this study the peak accompanying the word in contrastive focus is aligned significantly earlier. We will come back to this in the discussion.

\section{F0 maximum}

Table 3 gives the results for the F0 maximum of the noun, the adjective and the difference between the two (in ERB).

For the F0 maximum on the noun, a significant difference was found between broad focus and contr. $\mathrm{N}, \beta=-0.0023, t=-6.0, p=.001$, and between broad focus and contr. A, $\beta=-0.0023, t=$ $-6.0, p=.001$. That is, the F0 maximum was significantly higher in broad focus (mean $=5.35)$ than 
Table 3. F0 maximum of the noun, the adjective and the difference (noun-adjective) for three focus types (in ERB).

\begin{tabular}{|c|c|c|c|c|c|c|c|c|c|}
\hline \multirow[t]{2}{*}{ Focus type } & \multicolumn{3}{|c|}{ Noun } & \multicolumn{3}{|c|}{ Adjective } & \multicolumn{3}{|c|}{ Difference } \\
\hline & $N$ & Mean & SD & $N$ & Mean & SD & $N$ & Mean & SD \\
\hline Broad & 272 & 5.35 & 1.06 & 240 & 4.85 & 0.90 & 212 & 0.84 & 1.28 \\
\hline Contr. N & 273 & 5.17 & 0.98 & 237 & 4.74 & 0.89 & 212 & 0.70 & 1.45 \\
\hline Contr. A & 269 & 5.14 & 0.97 & 242 & 4.77 & 0.96 & 210 & 0.58 & 1.10 \\
\hline
\end{tabular}

in contr. $\mathrm{N}($ mean $=5.17)$ and contr. $\mathrm{A}($ mean $=5.14)($ Table 3$)$. This does not correspond to, for instance, Madrid Spanish (Face, 2001, 2002). Interestingly, O'Rourke (2005, 2012) also found that several Cusco Spanish speakers used lower peaks on the initial subject in contrastive focus than in broad focus.

Concerning the F0 maximum on the adjective, there was also a significant effect between broad focus and contr. $\mathrm{N}, \beta=-0.0012, t=-2.0, p=.006$. The F0 maximum was significantly higher in broad focus (mean $=4.85)$ than in contr. $\mathrm{N}($ mean $=4.74)$ (Table 3$)$. The results do not correspond to other Spanish varieties, where the F0 maximum of the adjective is higher in contrastive focus than in broad focus (e.g. Face [2001] for Madrid Spanish). Moreover, there is no post-focal pitch reduction when the noun is in contrastive focus (i.e. a significantly lower F0 maximum on the postfocal adjective in contr. $\mathrm{N}$ than in the other contexts).

The utterances showed a general tendency of a gradual decline of F0 (Gussenhoven, 2004), leading to a positive difference in the F0 maximum of the noun and that of the adjective. For this difference a significant effect was found between broad focus and contr. A, $\beta=-0.0050, t=-2.9$, $p=.004$. That is, the difference was significantly larger in broad focus (mean $=0.84)$ than in contr. A (mean $=0.58)$ (Table 3$)$. It was not significantly larger in contr. $\mathrm{N}$ than in the other contexts, confirming that there is no post-focal pitch reduction.

\section{Local range}

The results for the local range of the noun, the adjective and the difference between the two (in ERB) are summarized in Table 4.

There were no significant differences between the focus types for the local range of the noun, the adjective and the difference between the two. Local range is thus not used to encode focus, unlike in O'Rourke (2005).

Table 4. Local range of the noun, the adjective and the difference (noun-adjective) for three focus types (in ERB).

\begin{tabular}{|c|c|c|c|c|c|c|c|c|c|}
\hline \multirow[t]{2}{*}{ Focus type } & \multicolumn{3}{|c|}{ Noun } & \multicolumn{3}{|c|}{ Adjective } & \multicolumn{3}{|c|}{ Difference } \\
\hline & $N$ & Mean & SD & $N$ & Mean & SD & $N$ & Mean & SD \\
\hline Broad & 274 & 0.82 & 0.64 & 239 & 0.62 & 0.61 & 213 & 0.09 & 1.23 \\
\hline Contr. N & 272 & 0.78 & 0.60 & 234 & 0.54 & 0.49 & 209 & 0.11 & 1.42 \\
\hline Contr. A & 265 & 0.72 & 0.53 & 240 & 0.65 & 0.58 & 211 & -0.04 & 1.00 \\
\hline
\end{tabular}




\section{Duration}

Table 5 summarizes the results for the durations of the stressed syllable for the noun, the adjective and the difference between the two (in milliseconds). Table 6 concerns the durations of the word.

Regarding the noun, the durations of the stressed syllable and word did not differ significantly between the focus types. In contrast, for the adjective significant effects were found between contr. A and broad focus, $\beta=0.0628, t=3.77, p=.001$, for the stressed syllable and $\beta=0.0575, t=3.97$, $p=.001$ for the word, and between contr. A and contr. $\mathrm{N}, \beta=-0.0745, t=-4.46, p=.001$ for the stressed syllable, and $\beta=-0.0705, t=-4.89, p=.001$ for the word. The adjective was significantly longer in contr. A (mean $=216.09 \mathrm{~ms}$ for the stressed syllable; $495.28 \mathrm{~ms}$ for the word) than in broad focus (mean $=203.57$ for the stressed syllable; $473.51 \mathrm{~ms}$ for the word) and in contr. $\mathrm{N}$ (mean $=203.58 \mathrm{~ms}$ for the stressed syllable; $467.68 \mathrm{~ms}$ for the word) (Tables 5 and 6).

In addition, for the stressed syllable there was a significant effect for the difference (adjectivenoun) between contr. A and contr. $\mathrm{N}, \beta=18.763, t=3.73, p=.001$. That is, the difference between the noun and the adjective was larger in contr. A (mean =81.11) than in contr. $\mathrm{N}($ mean $=74.70)$ (Table 5). This means that the stressed syllable of the adjective was significantly longer relative to the noun in contr. A than in contr. N.

The results of this study showed that lengthening is used as a focus strategy in Cusco Spanish, as in some other Spanish varieties (De-la-Mota (1997) for Peninsular Spanish; Face (2001, 2002) for Madrid Spanish; Kim \& Avelino (2003) for Mexican Spanish). However, significant effects were only found for the (relative) duration of the adjective.

\section{Discussion and conclusion}

This study examined whether Quechua-Spanish bilinguals use prosodic features to distinguish broad from contrastive focus within the Spanish NP. A dialogue game was designed to elicit broad

Table 5. Duration of the stressed syllable of the noun, the adjective and the difference (adjective-noun) for three focus types (in $\mathrm{ms}$ ).

\begin{tabular}{|c|c|c|c|c|c|c|c|c|c|}
\hline \multirow[t]{2}{*}{ Focus type } & \multicolumn{3}{|c|}{ Noun } & \multicolumn{3}{|c|}{ Adjective } & \multicolumn{3}{|c|}{ Difference } \\
\hline & $N$ & Mean & SD & $N$ & Mean & SD & $N$ & Mean & SD \\
\hline Broad & 308 & 189.58 & 55.72 & 313 & 203.57 & 53.93 & 306 & 13.58 & 73.14 \\
\hline Contr. N & 309 & 192.39 & 55.35 & 309 & 203.58 & 58.01 & 308 & 10.99 & 74.70 \\
\hline Contr. A & 296 & 189.27 & 62.17 & 306 & 216.09 & 64.48 & 293 & 25.18 & 81.11 \\
\hline
\end{tabular}

Table 6. Duration word of the noun, the adjective and the difference (adjective-noun) for three focus types (in $\mathrm{ms}$ ).

\begin{tabular}{|c|c|c|c|c|c|c|c|c|c|}
\hline \multirow[t]{2}{*}{ Focus type } & \multicolumn{3}{|c|}{ Noun } & \multicolumn{3}{|c|}{ Adjective } & \multicolumn{3}{|c|}{ Difference } \\
\hline & $N$ & Mean & SD & $N$ & Mean & SD & $N$ & Mean & SD \\
\hline Broad & 305 & 396.05 & 117.18 & 311 & 473.51 & 95.53 & 304 & 79.47 & 129.83 \\
\hline Contr. N & 310 & 388.97 & 104.52 & 310 & 467.68 & 97.96 & 310 & 81.34 & $|20.3|$ \\
\hline Contr. A & 297 & 398.99 & 125.32 & 310 & 495.28 & 101.89 & 298 & 95.55 & $14 \mid .25$ \\
\hline
\end{tabular}


focus, contrastive focus on the noun (non-final word) and contrastive focus on the adjective (final word). The results showed differences with other Spanish varieties.

As discussed above, in many Spanish varieties contrastive focus on a non-final word is indicated by early peak alignment, whereas broad focus involves late alignment. Additional prominence-lending features accompanying the word in contrastive focus are a higher F0 maximum, a wider local range, post-focal pitch reduction and longer durations of the stressed syllable and word.

This study revealed that Cusco Spanish uses some prominence-lending features to mark focus, although differently than other Spanish varieties. Concerning the adjective, the stressed syllable and word were significantly longer in contr. A than in contr. N. Lengthening is thus used to distinguish focus types in final position. This was not found for the non-final word.

Contrary to what was found for other Spanish varieties, the F0 maximum was higher in broad focus than in both contrastive focus contexts. O'Rourke $(2005,2012)$ also found that elements were more prominent in broad focus than in contrastive focus; the Cusco participants in her study (on read speech) used higher peaks and wider global and local ranges in broad focus than in contrastive focus. Interestingly, Hanssen, Peters, and Gussenhoven (2008) found higher peaks for broad focus than for contrastive focus in Dutch. More research is needed to further explore the relationship between an increased pitch and broad focus.

The results furthermore revealed that in Cusco Spanish the contrast between early and late peak alignment is not used to distinguish between broad focus, contr. $\mathrm{N}$ and contr. A. The loss of this phonological contrast could be due to contact with Quechua, in which peak alignment is mostly early (O'Rourke, 2005, 2009). In O'Rourke $(2005,2012)$ there was no contrast in peak alignment in the Spanish of Quechua-Spanish bilinguals either. The contrast in peak alignment also disappeared in other contact situations (Colantoni \& Gurlekian, 2004; Elordieta, 2003), demonstrating that shared features are vulnerable to change. Early peak alignment is a common feature of Quechua and Spanish, but while in Quechua peaks are generally aligned early, in most Spanish varieties (e.g. Peninsular Spanish) early alignment is limited to contrastive focus and the nuclear accent. Colantoni and Gurlekian (2004) and Simonet $(2008,2011)$ showed convergence at the prosodic level for related languages in contact (Spanish-Italian and Spanish-Catalan). For contact between Spanish and Quechua, typologically different languages, Sánchez (2003) showed convergence at the syntax-pragmatics level. With O'Rourke $(2005,2012)$ and Muntendam (2012), the present study tentatively suggests that Quechua-Spanish contact also leads to prosodic convergence. Data from monolingual Quechua speakers is needed to explain this change in more detail. Another question is whether change is limited to shared features or whether new prosodic features can be borrowed from another language as well. Future research could determine restrictions on contact-induced prosodic change.

Importantly, in this study the peak on the adjective was aligned significantly earlier in contr. A than in the other contexts. For women, this was also true for the noun in contr. N. Although the description of pitch accents falls beyond the scope of this paper, these results contribute to studies on the phonological inventory across varieties (e.g. Prieto \& Roseano, 2010). Similar differences in early alignment within the stressed syllable were reported for Argentinean Spanish in contact with Italian (Gabriel, 2006; Gabriel, Feldhausen, \& Pešková, 2009). Like Quechua, Italian has no phonological contrast in peak alignment: the prenuclear peak in Neapolitan Italian broad focus declaratives falls on the stressed syllable (Face \& D'Imperio, 2005). Our results for Cusco Spanish might indicate a shift from the contrast between early and late alignment to a contrast within the stressed syllable. It seems that peak alignment as a prominence-lending feature is not completely lost in contact, but its exact properties were changed. More research, particularly an acoustic analysis of monolingual Quechua data, is needed to confirm this hypothesis and to explain the prosodic 
change in Quechua-Spanish contact more adequately. In addition, an analysis of the Quechua data of this study will shed light on a potential influence from Spanish on Quechua.

Given that the inclusion of the fixed effects Education and Type of bilingual did not improve the model fit, the prosodic change in the Spanish NP does not seem to be restricted to a particular group of speakers. Rather, it appears to be extended to the entire group of bilingual adults. In contrast, as mentioned above, there was an effect of Gender on peak alignment on the noun. More research is needed to study the role of gender and speaker variation in the Quechua-Spanish contact situation.

There are limitations to this study. Firstly, it was revealed that Quechua-Spanish bilinguals use prosody differently to encode focus within the NP in Spanish. A perception study is needed to explore to what extent these bilinguals perceive the prosody of focus in other Spanish varieties. Secondly, the prosody of the Cusco Spanish NP was compared to previous studies on other Spanish varieties, which mainly concerned prosody at the sentence level. The game needs to be conducted by a control group of Spanish monolinguals to show the differences between Cusco Spanish and other Spanish varieties and to exclude the possibility of a task effect. Because the findings for F0 maximum and peak alignment support O'Rourke's $(2005,2012)$ findings for read speech, a task effect is unlikely. Thirdly, this study was limited to broad and contrastive focus. The data on neutral narrow focus need to be analyzed to better understand the interaction of prosody and focus within the NP. Future research should also take into account other prominence-lending features (e.g. global range and intensity).

\section{Acknowledgements}

We would like to thank our participants in Conchacalla, Peru. Also, we are thankful to Rafael Mercado for his help with the Quechua part of this project, to Marco van de Ven for his help with the statistics, and to José Ignacio Hualde and Pilar Prieto for their valuable comments. All errors are of course ours.

\section{Funding}

This work was supported by the Foundation Nijmegen University Fund (SNUF); Royal Netherlands Academy of Arts and Sciences (KNAW); and the ERC project 'Traces of Contact' (grant number 230310).

\section{Notes}

1. The following abbreviations are used: $\mathrm{ACC}=$ accusative; $\mathrm{FOC}=$ focus; $\mathrm{PERF}=$ perfective; $\mathrm{PL}=$ plural; $\mathrm{SG}=$ singular; $\mathrm{TOP}=$ topic .

2. The drawings were adopted from http://crl.ucsd.edu/ aszekely/ipnp/method/getpics/getpics.html, www. midisegni.it, www.schoolplaten.com and www.hetkleineloo.nl, and adjusted for the experiment.

3. We would like to thank an anonymous reviewer for the suggestion to only include Focus and Gender as fixed effects.

\section{References}

Armstrong, M. (2010). Puerto Rican Spanish intonation. In P. Prieto \& P. Roseano (Eds.), Transcription of intonation of the Spanish language (pp. 155-189). München, Germany: Lincom Europa.

Astruc, L., Mora, E., \& Rew, S. (2010). Venezuelan Andean Spanish intonation. In P. Prieto \& P. Roseano (Eds.), Transcription of intonation of the Spanish language (pp. 191-226). München, Germany: Lincom Europa.

Baayen, R. (2011). LanguageR: Data sets and functions with 'Analyzing linguistic data: A practical introduction to statistics.' R package version 1.4. Retrieved from http:/CRAN.R-project.org/ package=language $R$ 
Baayen, R., Davidson, D., \& Bates, D. (2008). Mixed-effects modeling with crossed random effects for subjects and items. Journal of Memory and Language, 59, 390-412.

Bates, D., Maechler, M., \& Bolker, B. (2011). Lme4: Linear mixed-effects models using S4 classes. R package version 0.999375-42. Retrieved from http://CRAN.R-project.org/package=lme4

Boersma, P., \& Weenink, D. (2010). Praat: doing phonetics by computer. Version 5.1.44. Retrieved from http://www.praat.org/

Bullock, B. (2009). Prosody in contact in French: A case study from a heritage variety in the USA. International Journal of Bilingualism, 13, 165-194.

Cabrera-Abreu, M., \& Vizcaíno-Ortega, F. (2010). Canarian Spanish intonation. In P. Prieto \& P. Roseano (Eds.), Transcription of intonation of the Spanish language (pp. 87-121). München, Germany: Lincom Europa.

Cerrón-Palomino, R. (1987). Lingüística quechua. Cusco, Peru: Centro de estudios rurales andinos Bartolomé de las Casas.

Colantoni, L. (2011). Broad-focus declaratives in Argentine Spanish contact and non-contact varieties. In C. Gabriel \& C. Lleó (Eds.), Intonational phrasing in Romance and Germanic. Cross-linguistic and bilingual studies (pp. 183-212). Amsterdam, The Netherlands/Philadelphia, PA: John Benjamins.

Colantoni, L., \& Gurlekian, J. (2004). Convergence and intonation: Historical evidence from Buenos Aires Spanish. Bilingualism: Language and Cognition, 7, 107-119.

Cole, P. (1982). Imbabura quechua. Amsterdam, The Netherlands: North Holland Publishing Company.

Cruttenden, A. (2006). The de-accenting of old information: a cognitive universal? In G. Bernini \& M. Schwartz (Eds.), Pragmatic organisation in the languages of Europe (pp. 311-355). The Hague, The Netherlands: Mouton de Gruyter.

Cusihuamán, A. (1976/2001). Gramática quechua Cuzco-Collao. Cusco, Peru: Centro de estudios regionales andinos Bartolomé de las Casas.

De-la-Mota, C. (1997). Prosody of sentences with contrastive new information in Spanish. In A. Botinis, G. Kouroupetroglou, \& G. Carayiannis (Eds.), Intonation: Theory, models and applications. Proceedings of an ESCA workshop (pp.75-78).

Elordieta, G. (2003). The Spanish intonation of speakers of a Basque pitch-accent dialect. Catalan Journal of Linguistics, 2, 67-95.

Estebas-Vilaplana, E., \& Prieto, P. (2010). Castilian Spanish intonation. In P. Prieto \& P. Roseano (Eds.), Transcription of intonation of the Spanish language (pp. 17-46). München, Germany: Lincom Europa.

Face, T. (2001). Focus and early peak alignment in Spanish intonation. Probus, 13, 223-246.

Face, T. (2002). Local intonational marking of Spanish contrastive focus. Probus, 14, 71-92.

Face, T. (2003). Intonation in Spanish declaratives: Differences between lab speech and spontaneous speech. Catalan Journal of Linguistics, 2, 115-131.

Face, T., \& D'Imperio, M. (2005). Reconsidering a focal typology: Evidence from Spanish and Italian. Italian Journal of Linguistics, 17, 271-289.

Faller, M. (2002). Semantics and pragmatics of evidentials in Cuzco Quechua. Dissertation, Stanford University.

Gabriel, C. (2006). Focal pitch accents and subject positions in Spanish: Comparing close-to-standard varieties and Argentinean Porteño. In: R. Hoffmann \& H. Mixdorff (Eds.), Speech prosody 2006. Dresden, Germany: TUDpress Verlag der Wissenschaften.

Gabriel, C., Feldhausen, I., \& Pešková, A. (2009). Contrastive and neutral focus in porteño Spanish. Paper presented at the $31^{\text {st }}$ Annual Meeting of the Deutsche Gesellschaft für Sprachwissenschaft (DGfS), Osnabrück, 4 March 2009.

Gabriel, C., Feldhausen, I., Pešková, A., Colantoni, L., Lee, S., Arana, V., \& Labastía, L. (2010). Argentinian Spanish intonation. In P. Prieto \& P. Roseano (Eds.), Transcription of intonation of the Spanish language (pp. 205-317). München, Germany: Lincom Europa.

Gussenhoven, C. (2004). The Phonology of tone and intonation. Cambridge, UK: Cambridge University Press. 
Gussenhoven, C. (2007). Types of focus in English. In C. Lee, M. Gordon, \& D. Büring (Eds.), Topic and focus: Cross-linguistic perspectives on meaning and intonation (pp. 83-100). Heidelberg, Germany; New York, NY; London, UK: Springer.

Hanssen, J., Peters, J., \& Gussenhoven, C. (2008). Prosodic effects of focus in Dutch declaratives. In A. Barbosa, S. Madureira, \& C. Reis (Eds.), Proceedings of the 4th International Conferences on Speech Prosody (pp. 609-612). Campinas, Brazil: Editora RG.

Hermes, D., \& Van Gestel, J. (1991). The frequency scale of pitch intonation. Journal of the Acoustical Society of America, 90, 97-102.

Kim, S., \& Avelino, H. (2003). An intonational study of focus and word order variation in Mexican Spanish. In E. Herrera \& P. Martín Butragueño (Eds.), La tonía: Dimensiones fonéticas y fonológicas (pp. 357374). Mexico City, Mexico: El colegio de México.

López-Bobo, J., \& Cuevas-Alonso, M. (2010). Cantabrian Spanish intonation. In P. Prieto \& P. Roseano (Eds.), Transcription of intonation of the Spanish language (pp. 49-85). München, Germany: Lincom Europa.

Mazzoni, D., \& Dannenberg, R. (2010). Audacity. A free, cross-platform, audio editor. Version 1.2.6. Retrieved from http://audacity.sourceforge.net/

Muntendam, A. (2009). Linguistic transfer in Andean Spanish: Syntax or pragmatics? Dissertation, University of Illinois at Urbana-Champaign.

Muntendam, A. G. (2012). Information structure and intonation in Andean Spanish. eLanguage. Retrieved from http://elanguage.net/journals/lsameeting/issue/view/2012

Muntendam, A. G. (2013). On the nature of cross-linguistic transfer: A case study of Andean Spanish. Bilingualism: Language and Cognition, 16, 111-131.

Muysken, P. (1995). Focus in Quechua. In K. Kiss (Ed.), Discourse configurational languages (pp. 375-393). New York, NY; Oxford, UK: Oxford University Press.

O'Rourke, E. (2005). Intonation and language contact: A case study of two varieties of Peruvian Spanish. Dissertation, University of Illinois at Urbana-Champaign.

O'Rourke, E. (2009). Phonetics and phonology of Cuzco Quechua declarative intonation: An instrumental analysis. Journal of the International Phonetic Association, 39, 291-312.

O’Rourke, E. (2010). Ecuadorian Andean Spanish. In P. Prieto \& P. Roseano (Eds.), Transcription of intonation of the Spanish language. München, Germany: Lincom Europa.

O'Rourke, E. (2012). The realization of contrastive focus in Peruvian Spanish intonation. Lingua, 122, 494-510.

Parker, G. (1969). Ayacucho Quechua grammar and dictionary. The Hague, The Netherlands, Paris, France: Mouton.

Prieto, P., \& Roseano, P. (Eds.) (2010). Transcription of intonation of the Spanish language. München, Germany: Lincom Europa.

$\mathrm{R}$ Development Core Team (2011). R: A language and environment for statistical computing. $\mathrm{R}$ foundation for statistical computing. Retrieved from http://www.R-project.org/

Samanez-Flórez, D. (1996). Gramática del quechua del qosqo. Cusco, Peru: Academia Mayor de la Lengua Quechua.

Sánchez, L. (2003). Quechua-Spanish bilingualism: Interference and convergence in functional categories. Amsterdam, The Netherlands: John Benjamins.

Sánchez, L. (2010). The morphology and syntax of focus and topic: Minimalist inquiries in the Quechua periphery. Amsterdam, The Netherlands: John Benjamins.

Silva-Corvalán, C. (2008). The limits of convergence in language contact. Journal of Language Contact, 2, 213-224.

Simonet, M. (2008). Language contact in Majorca. An experimental sociophonetic approach. Dissertation, University of Illinois at Urbana-Champaign.

Simonet, M. (2011). Intonational convergence in language contact: Utterance-final F0 contours in CatalanSpanish bilinguals. Journal of the International Phonetic Association, 41, 157-184. 
Swerts, M., Krahmer, E., \& Avesani, C. (2002). Prosodic marking of information status in Dutch and Italian: a comparative analysis. Journal of Phonetics, 30, 629-654.

Thomason, S. (2001). Language contact: An introduction. Edinburgh, UK; Washington, DC: Edinburgh University Press; Georgetown University Press.

Thomason, S., \& Kaufman, T. (1988). Language contact, creolization, and genetic linguistics. Berkeley, CA; Los Angeles, CA; London, UK: University of California Press.

Van Leyden, K., \& Van Heuven, V. (2006). On the prosody of Orkney and Shetland dialects. Phonetica, 63, 149-174.

Willis, E. (2010). Dominican Spanish intonation. In P. Prieto \& P. Roseano (Eds.), Transcription of intonation of the Spanish language (pp. 123-153). München, Germany: Lincom Europa.

Zavala, V. (1999). Reconsideraciones en torno al español andino. Lexis, 23, 25-85.

Zubizarreta, M. (1999). Las funciones informativas: Tema y foco. In I. Bosque \& V. Demonte Barreto (Eds.), Gramática descriptiva de la lengua española, 3 (pp. 4217-4244). Madrid, Spain: Real Academia Española, Espasa Calpe.

\section{Author biographies}

Remy van Rijswijk is a PhD student of Linguistics at the Radboud University Nijmegen, The Netherlands. Her research interests include bilingualism, information structure and prosody.

Antje Muntendam is Assistant Professor of Linguistics at the Radboud University Nijmegen, The Netherlands. Her main research interests are bilingualism, language contact, information structure, syntax and prosody. 